\title{
Surgical Management of Chronic Bilateral Condylar Dislocation
}

\author{
${ }^{1}$ Dinesh C Sharma, ${ }^{2}$ Sunil Sharma, ${ }^{3}$ Punit Chitlangia, ${ }^{4}$ Amit
}

\begin{abstract}
Dislocation is the complete separation of the articular surfaces of a joint and fixation in an abnormal position. In case of mandibular dislocation, the normal anatomic relationship of the mandibular condyle with the glenoid fossa disrupts and condyle seats in an unfavorable position which is mostly anterior. Dislocation can be of acute and chronic subtypes. Acute dislocation is once in a lifetime event, but chronic dislocations are painful and distressing to the patient. There are various nonsurgical and surgical treatment options available in the literature but the most sought after method is eminectomy. A case of chronic dislocation treated surgically with eminectomy is reported here.
\end{abstract}

Keywords: Condylar dislocation, Eminectomy, Subluxation.

How to cite this article: Sharma DC, Sharma S, Chitlangia P, Amit. Surgical Management of Chronic Bilateral Condylar Dislocation. J Mahatma Gandhi Univ Med Sci Tech 2017;2(1):41-43.

\section{Source of support: Nil}

Conflict of interest: None

\section{INTRODUCTION}

Dislocation of mandibular condyle can be defined as displacement of the mandibular condyle anterior of and superior to the articular eminence which fails to selfreduce and resulted in the inability to close the mouth. ${ }^{1}$ Dislocation can occur in any direction but the most common occurrence is in an anterior direction in relationship to the articular eminence. Condylar dislocation can be further divided into unilateral or bilateral subtype depending on involvement of one or both temporomandibular joints (TMJs). Depending on frequency and event of occurrence, it can be acute, chronic, or recurrent in nature (Table 1$).^{2}$ Another classification was proposed

\footnotetext{
${ }^{1}$ Postgraduate Student, ${ }^{2}$ Professor and Head, ${ }^{3}$ Reader, ${ }^{4}$ Senior Lecturer

${ }^{1-4}$ Department of Oral and Maxillofacial Surgery, Mahatma Gandhi Dental College \& Hospital, Mahatma Gandhi University of Medical Sciences \& Technology, Jaipur, Rajasthan, India

Corresponding Author: Dinesh C Sharma, Postgraduate Student, Department of Oral and Maxillofacial Surgery, Mahatma Gandhi Dental College \& Hospital, Mahatma Gandhi University of Medical Sciences \& Technology, Jaipur, Rajasthan, India Phone: +919414500005, e-mail: drdinesh1812@gmail.com
}

Table 1: Treatment modalities for dislocation of temporomandibular joint

\begin{tabular}{ll}
\hline Acute dislocation & Recurrent and chronic dislocation \\
\hline $\begin{array}{l}\text { Manual reduction } \\
\text { Without local }\end{array}$ & Manual reduction \\
anesthesia & Followed by injection of sclerosing \\
With local anesthesia & agents into joint \\
With muscle relaxant & Followed by injection of Botulinum \\
Induction of gag reflex & Indirect reduction \\
& Via sigmoid notch \\
& Preauricular approach \\
& Direct reduction \\
& Restitution of capsular ligament \\
& Augmentation of articular eminence \\
& Eminectomy \\
& Condylotomy \\
& Myotomy \\
\hline
\end{tabular}

by Sir Astley Cooper in 1932. He introduced the terms complete dislocation (luxation) and imperfect dislocation (subluxation). He also proposed principles for diagnosis and treatment of dislocation of the lower jaw. ${ }^{3}$

\section{CASE REPORT}

A 32-year-old male patient reported to the Department of Oral and Maxillofacial Surgery, Mahatma Gandhi Dental College \& Hospital, Jaipur, Rajasthan, India, with the chief complaint of pain in front of ears on both the sides and inability to close the mouth. His medical history was insignificant and this was his ninth or tenth incidence of dislocation. Clinical examination revealed depression anterior to the tragus in the region of glenoid fossa and condyle on palpation both the sides. Joint movements were absent on both sides with persistent open bite and inability to occlude the teeth. Tenderness was present bilaterally in the temporal region. Mandible was protruded with open bite anteriorly and posteriorly and lips were incompetent. Interincisal mouth opening was $20 \mathrm{~mm}$. Orthopantomogram (OPG) revealed that bilateral condyles are dislocated from joint space and locked anterior to the articular eminence. An important feature was presence of very prominent articular eminence on both the sides. The surgery was planned using the OPG, in which the necessary measurements were taken to determine the amount of bone structure that had to be removed (Fig. 1). The surgery was performed under general anesthesia, using Myrhaug's 


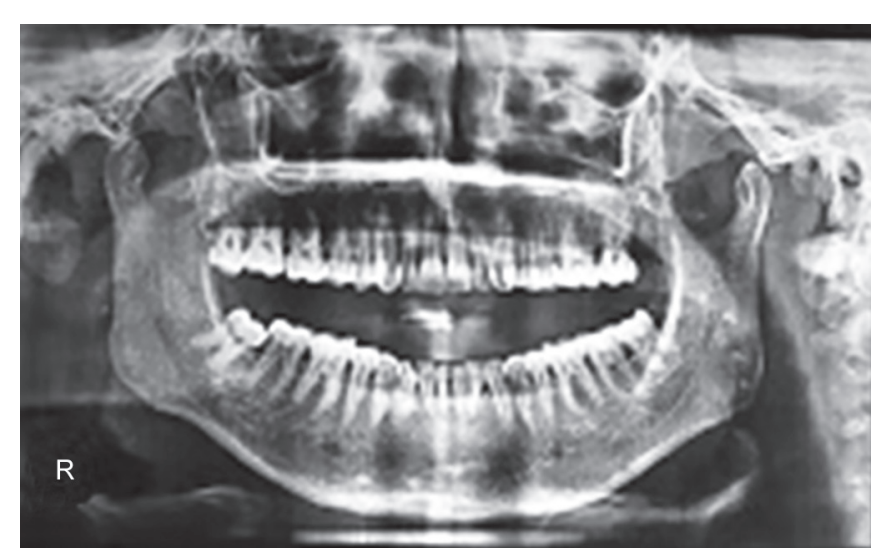

Fig. 1: Bilateral condylar dislocation (preoperative OPG)

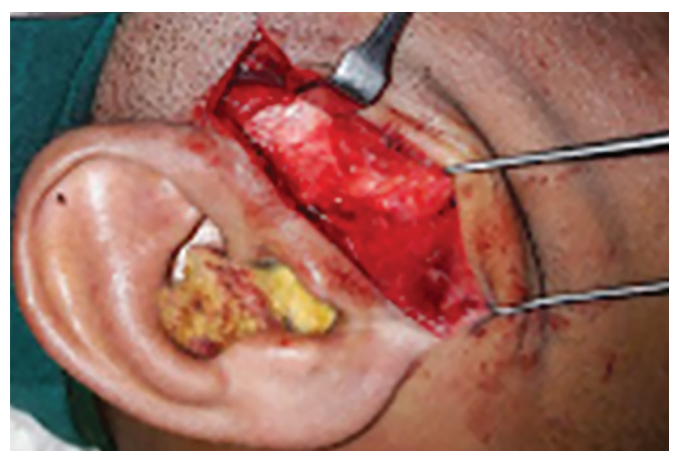

Fig. 3: Surgical exposure

procedure, by means of a bilateral preauricular access and osteotomy of the articular eminence (Figs 2 and 3). The osteotomy was concluded in the medial region with a chisel. Next, the region was flattened with drilling. The surgical procedure was evaluated postoperatively with OPG (Fig. 4), and during the postoperative follow-up, there were no new episodes of mandibular dislocation. The mouth opening at that point was $36 \mathrm{~mm}$, with no painful alterations of the TMJ in either the static or functional dynamic state.

\section{DISCUSSION}

Dislocation of the mandible is one of the earliest afflictions of the jaws to be described in the literature. The incidence of TMJ dislocation is more in females. The most common direction of dislocation is anterior. ${ }^{2}$ The stability of any joint depends on three factors: the integrity of ligaments, neuromuscular mechanism, and bony architecture of the joint surfaces. ${ }^{3}$ The problem can affect any age group from under the age of 10 years up to 79 years but is more common in second and third decade. ${ }^{3,4}$ It occurs as a combination of three factors: Laxity of mandibular and capsular ligaments, large bony eminence, and spasm of muscle. ${ }^{3}$ Recurrent and chronic cases can be reduced by surgical intervention.

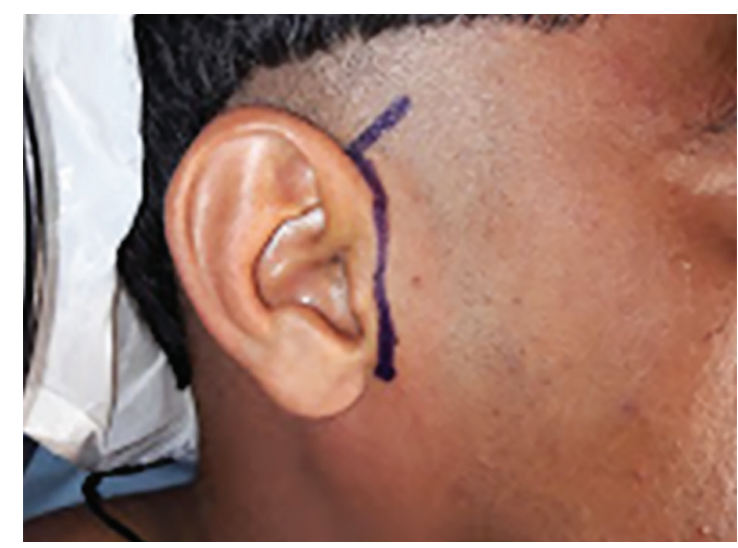

Fig. 2: Incision marking

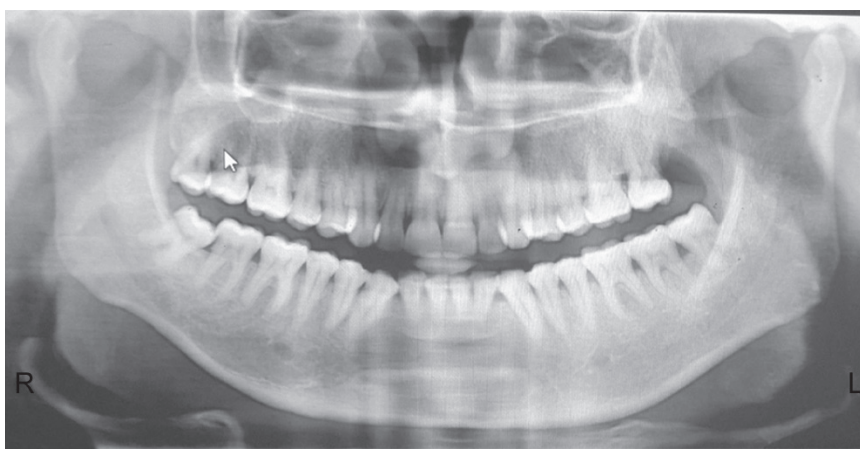

Fig. 4: Bilateral eminectomy (postoperative OPG)

When conservative approach does not respond then surgical techniques that limit or enhance the condylar path like direct reduction following surgical exposure of the joint, eminectomy, grafting the articular eminence, temporal myotomy, condylotomy, condylectomy, osteotomy should be adopted. Eminectomy has proven to be a versatile technique in the management of different types of patients, with different complexities and with no age limit. Mizuno et $\mathrm{al}^{5}$ reported two cases of long-standing dislocations treated with eminectomy; one case was of a 62-year-old woman with mandibular dislocation with some weeks of duration due to repeated vomiting and another of a 74-year-old patient with a mandibular dislocation of 57 days of duration. Both cases were treated by reduction under general anesthesia and followed by eminectomy. No recurrence was reported in both cases. ${ }^{5}$ Chronic dislocation of such long-standing duration generally over time develops fibrous adhesions between the disc, condyle, and articular eminence. Jaw muscles and ligaments also undergo fibrous changes.

Williamson et $\mathrm{al}^{6}$ reported a series of 20 cases of TMJ dislocation treated by eminectomy. He reported that "improvement was observed in the degree of pain, increasing the maximum mouth opening on average $9 \mathrm{~mm}$ after the surgery." 
Although condylar hypermobility might be expected because there is no articular eminence capable of containing it, the study by Undt et $\mathrm{al}^{7}$ did not show any changes in the joint movements preoperatively or postoperatively, indicating as a probable cause the presence of a fibrous scar in the anterior sector of the capsule that would prevent excessive movement. This situation is also demonstrated in the three cases presented here.

In terms of complications, the series of 14 patients by Undt et $\mathrm{al}^{8}$ showed that the complications were observed in three cases, these being fracture of the condylar head, persistence of the mandibular dislocation, and osteoarthrosis of the TMJ.

Surgical access is not observed as a complication in the postoperative esthetics or possible damage to the facial nerve; in fact, nowadays preauricular or endaural access is considered routine procedure. Horizontal access, on the zygomatic arch, investigated initially so as not to damage the facial nerve, did not present any differences when compared with preauricular access. ${ }^{9}$

Variations and modifications of the initial procedure have also been proposed by some authors. Gay-Escoda ${ }^{10}$ presented a series of 12 patients with eminectomy and repositioning of the temporal muscle instead of the articular eminence; he reported success in terms of the absence of dislocation recurrence and an almost 4-mm reduction in the maximum mouth opening after 1 year of follow-up.

Güven ${ }^{11}$ presented 12 cases of patients with recurrent dislocations who underwent eminoplasty, where a wedge osteotomy was performed from the posterior toward the anterior in the articular eminence, and a bone graft was installed to increase the eminence vertically; the author indicated good results with a reduction in the mouth opening to approximately $38 \mathrm{~mm}$ and with no dislocation recurrence.

In conclusion, the bilateral eminectomy for the management of TMJ dislocations to case of chronic mandibular dislocations is a completely viable, easy, and successful option. It has very minimal complications reported with high success rate and early postoperative relief and patient compliance. It is currently presented as a well-known procedure that is constantly being modified to optimize the indications and their results.

\section{REFERENCES}

1. Keith, DA. Surgery of the temporomandibular joint. 2nd ed. Boston Blackwell Scientific Publications. Chapter 10, Mandibular dislocation; p. 154-170.

2. Aquilina P, Vickers R, McKellar G. Reduction of a chronic bilateral temporomandibular joint dislocation with intermaxillary fixation and botulinum toxin A. Br J Oral Maxillofac Surg 2004 Jun;42(3):272-273.

3. Shorey CW, Campbell JH. Dislocation of the temporomandibular joint. Oral Surg Oral Med Oral Pathol Oral Radiol Endod 2000 Jun;89(6):662-668.

4. Tasanen A, Lamberg MA. Closed condylotomy in the treatment of recurrent dislocation of the mandibular condyle. Int J Oral Surg 1978 Feb;7(1):1-6.

5. Mizuno A, Suzuki S, Motegi K. Articular eminectomy for long-standing luxation of the mandible. Report of 2 cases. Int J Oral Maxillofac Surg 1988 Oct;17(5):303-306.

6. Williamson RA, McNamara D, McAuliffe W. True eminectomy for internal derangement of the temporomandibular joint. Br J Oral Maxillofac Surg 2000 Oct;38(5):554-560.

7. Undt G, Kermer C, Piehslinger E, Rasse M. Treatment of recurrent mandibular dislocation, Part I: LeClerc blocking procedure. Int J Oral Maxillofac Surg 1997 Apr;26(2):92-97.

8. Undt G, Kermer C, Rasse M. Treatment of recurrent mandibular dislocation, Part II: eminectomy. Int J Oral Maxillofac Surg 1997 Apr;26(2):98-102.

9. Pogrel MA. Articular eminectomy for recurrent dislocation. Br J Oral Maxillofac Surg 1987 Jun;25(3):237-243.

10. Gay-Escoda C. Eminectomy associated with redirectioning of the temporal muscle for treatment of recurrent TMJ dislocation. J Craniomaxillofac Surg 1987 Dec;15(6):355-358.

11. Güven O. Management of chronic recurrent temporomandibular joint dislocations: a retrospective study. J Craniomaxillofac Surg 2009 Jan;37(1):24-29. 